\title{
POLÍTICA NACIONAL DE RESÍDUOS SÓLIDOS: MEIO AMBIENTE COMO DIREITO FUNDAMENTAL?
}

\author{
STATE OF ENVIRONMENTAL LAW: ENVIRONMENT \\ AS A FUNDAMENTAL LAW? \\ Chaiane Ferrazza Gomes ${ }^{1}$ \\ Lisianne Pintos Sabedra Ceolin ${ }^{2}$
}

Graduação em

Administração pela

Universidade da Região

da Campanha (2010) e

graduação em Jornalismo

pela Universidade Federal

do Pampa (2010). É

mestranda do Programa

de Pós-Graduação em

Políticas Públicas (PPGPP)

da mesma universidade.

Tem experiência na área

de Administração, com

ênfase em Administração de Empresas.

2

Doutora em Direito pela PUCRS, na Área de

Concentração Fundamentos Constitucionais do Direito

Público e do Direito Privado.

Possui graduação em Direito

pela Pontifícia Universidade

Católica do Rio Grande do

Sul (2001) e mestrado em

Direito pela Universidade

de Caxias do Sul (2006).

Atuou como docente na

Pontifícia Universidade

Católica do Rio Grande do

Sul, Campus Uruguaiana

(2003-2009). Atualmente,

é professora adjunta da

Universidade Federal do

Pampa - UNIPAMPA
RESUMo: Este artigo tem por objetivo compreender o conceito de Estado de Direito Ambiental e realizar uma discussão acerca da sua concretização, sugerindo formas para que ele possa tornar-se realidade, trazendo para a discussão a Política Nacional de Resíduos Sólidos (PNRS), instituída pela Lei n. 12.305/2010. Antes disso, trouxe-se um resgate bibliográfico do papel do Estado perante o meio ambiente antes e após a Constituição de 1988 até se chegar ao conceito de Estado de Direito Socioambiental. Para, então, em um segundo momento tecer uma discussão acerca de sua efetiva concretização no que diz respeito ao direito a um meio ambiente sadio e equilibrado como um direito fundamental. Percebeu-se através da literatura apurada e da análise do PNRS que, após décadas de omissão em relação ao meio ambiente, o Estado ensaia os primeiros passos rumo a um Estado considerado ambiental, porém também se percebeu que o desafio é grande, pois a implementação de políticas públicas ambientais enfrenta diversas dificuldades, desde financeiras até a falta de informações. Foi constatado, também, que uma possível solução para esse cenário envolve muitos fatores, sendo três deles imprescindíveis: acesso à informação, consciência coletiva e participação popular.

palavras-chave: Estado; Meio ambiente; Estado de Direito Ambiental; Direitos fundamentais.

AbStract: This article aims to understand the concept of the State of Environmental Law and to carry out a discussion about its implementation, suggesting ways for it to become a reality, bringing to the discussion the National Solid Waste Policy (PNRS), instituted by Law n. 12,305 / 2010. Before that, a bibliographical rescue of the role of the State before the environment was introduced before and after the Constitution of 1988 until arriving at the concept of State of Socioambiental Right. Then, in a second moment, a discussion about its actual realization regarding the right to a healthy and balanced environment as a fundamental right. It was noticed through the accurate literature and the analysis of the PNRS that, after decades of omission in relation to the environment, the State rehearses the first steps towards a state considered environmental, but also realized that the challenge is great, since the implementation of environmental public policies faces several difficulties, from financial to lack of information. It was also observed that a possible solution to this scenario involves many factors, three of them essential: access to information, collective awareness and popular participation.

KEYwORDs: State; Environment; State of Environmental Law; Fundamental rights. 
1- “Uma fase do desenvolvimento da sociedade moderna, onde os riscos sociais, políticos, ecológicos e individuais, criados pelo momento da inovação, iludem cada vez mais as instituições de controle e proteção da sociedade industrial" (BECK, 2011, p. 28).

\section{INTRODUÇÃO}

Embora seja vasta a discussão sobre o termo meio ambiente e suas dimensões, aqui usaremos a concepção de Silva $(1998$, p. 2) que o define como "a interação do conjunto de elementos naturais, artificiais e culturais que propiciem o desenvolvimento equilibrado da vida em todas as suas formas". Isso, pois, ele apresenta uma amplitude maior que àquela concebida pelo Plano Nacional de Meio Ambiente: "conjunto de definições, leis, influências, alterações e interações de ordem física, química e biológica, que permite, abriga e rege a vida em todas as suas formas" (BRASIL, 1981, p. 1). Assim, quando se menciona meio ambiente neste artigo refere-se ao conjunto de recursos naturais, artificiais e culturais, os quais são responsáveis por um desenvolvimento equilibrado da vida em todas as suas formas.

Como afirma Benjamin (2010, p. 77), "a riqueza de "terras e arvoredos", que surpreendeu e, possivelmente, encantou Pero Vaz de Caminha em 1500, finalmente foi reconhecida pela Constituição brasileira de 1988, passados 488 anos da chegada dos portugueses ao Brasil". Essa afirmação foi trazida para demonstrar o lapso de tempo em que os recursos naturais do Brasil ficaram a mercê da proteção do Estado, pois embora nas décadas de 6o, 70 e 80 tivessem tido atos do governo para regularizar algumas atividades nocivas aos recursos naturais, a tutela do Estado em relação ao meio ambiente só foi legitimada em 1988.

Frente a essa realidade de omissão do Estado em relação aos recursos naturais, não é de causar espanto quando se fala que vivemos em uma Sociedade de Risco ${ }^{1}$. De acordo com Rodrigues, Fernandes e Philippi Jr. (2011, p. 397-398), “o processo de industrialização conduziu o Brasil, a partir da década de 40, à formação de uma base industrial e de uma urbanização hoje considerada, pelas suas características, incompatível com o paradigma da sustentabilidade". Como bem afirmam os autores, a sustentabilidade ainda é considerada um paradigma na medida em que prevê a utilização dos recursos naturais de forma a não extingui-los.

Com a promulgação da Constituição de 1988, finalmente o meio ambiente foi elevado a direito fundamental, cabendo ao Estado, juntamente com a sociedade, a sua tutela. Desde então, passou-se a discutir um novo modelo de Estado pautado por uma maior preocupação com o meio ambiente frente à mercantilização através da conscientização do indivíduo e da coletividade, o qual se chama de Estado de Direito Socioambiental. Contudo, a concretização dessa construção teórica constitui-se no grande desafio do século XXI, na medida em que se são postos a frente os recursos naturais esgotáveis e o desenvolvimento econômico.

Frente a isso, este artigo tem por objetivo compreender o conceito de Estado de Direito Ambiental e discutir acerca da sua concretização, sugerindo formas para que ele possa tornar-se realidade, trazendo para a discussão a Política Nacional de Resíduos Sólidos (PNRS), instituída 
pela Lei n. 12.305/2010. Antes disso, trouxe-se um resgate bibliográfico do papel do Estado perante o meio ambiente antes e após a Constituição de 1988 até se chegar ao conceito de Estado de Direito Socioambiental. Para, então, em um segundo momento, tecer uma discussão acerca de sua efetiva concretização no que diz respeito ao direito a um meio ambiente sadio e equilibrado como um direito fundamental.

Percebeu-se que, após décadas de omissão em relação ao meio ambiente, o Estado ensaia os primeiros passos rumo a um Estado considerado ambiental, também se percebeu que o desafio é grande, pois a implementação de políticas públicas ambientais enfrenta diversas dificuldades, desde financeiras até a falta de informações. Foi constatado, também, que uma possível solução para esse cenário envolve muitos fatores, porém três deles são imprescindíveis: acesso à informação, consciência coletiva e participação popular.

\section{REFERENCIAL TEÓRICO}

\section{ESTADO E MEIO AMBIENTE NO BRASIL}

De acordo com O'Donnelll (2011), o Estado deve ser conceituado de três formas:

[primeiro como] entidade territorial que delimita quem são seus cidadãos (dãs) políticos (as); segundo como um sistema legal que promulga e respalda a atribuição dos direitos, liberdades e obrigações correspondentes, e terceiro [...] como um conjunto de burocracias estatais que atuam em consonância básica com a efetividade desses direitos, liberdades e obrigações (O'DONNELL, 2011, p. 39).

Nesse conceito de Estado preconizado por O'Donnell (2011) verifica-se que ao Estado são atribuídas três características fundamentais: território, leis e burocracias. Sendo assim, Estado seria um território que delimita quem são os indivíduos que estão submetidos a um conjunto de leis que emanam deveres e obrigações, as quais cabem a um conjunto de burocracias estatais executá-las e cobrá-las dos seus cidadãos.

Já a concepção de Estado Moderno trazida por Schiera (1998) atribui dois novos elementos para entender o conceito de Estado: o poder e a administração de conflitos:

Trata-se de uma organização das relações sociais (poder) por meio de procedimentos técnicos preestabelecidos (instituições, administração), úteis para a prevenção e neutralização dos casos de conflito e para o alcance dos fins terrenos que as forças dominadoras na estrutura social reconhecem como próprias e impõem como gerais a todo o país (SCHIERA, 1998, p. 427). 
Nessa concepção de Schiera (1998) são enfatizadas as relações de poder do Estado, que se dão através de instrumentos administrativos os quais têm a função de fazer cumprir deveres e cobrar obrigações visando prevenir e neutralizar possíveis conflitos dentro de uma estrutura social. Nesse sentido, Weber (1999, p. 526) afirma que o Estado "é uma relação de dominação de homens sobre homens, apoiada no meio da coação legítima (quer dizer, considerada legítima). Para que ele subsista, as pessoas dominadas têm que se submeter à autoridade invocada pelas que dominam no momento dado".

Porém, os indivíduos apenas se submetem a essas relações de poder e coerção, pois esperam em troca uma contrapartida do Estado, ou seja, esperam que os seus direitos individuais sejam garantidos. Essa é uma das concepções de Émile Durkheim sobre o Estado, conforme sintetiza Saccol (2012):

Para ele [Durkheim] um elemento essencial é que todo grupo político é a oposição entre governantes e governados, entre a autoridade e os que lhe são submetidos. Essas sociedades diferenciam-se das primitivas devido à proteção que é prestada aos seus membros. O indivíduo pelo simples fato de nascer tem certos direitos que o Estado deve garantir. O Estado é um organizador da vida social, sendo independente dela (SACCOL, 2012, p. 98).

Dessa forma, Estado pode ser entendido como um espaço territorial dotado de leis e instrumentos para que se possa fazer cumprir deveres e cobrar obrigações de seus indivíduos, exercendo poder coercitivo e administrando conflitos, ou seja, organizando a vida social. Porém, esses indivíduos apenas se submetem a esse poder coercitivo, pois esperam que seus direitos individuais sejam assegurados pelo Estado. E, dentre esses direitos, a partir da Constituição de 1988, está o de contar com um meio ambiente ecologicamente equilibrado, como está contido no Art. 225, da Carta Magna: "todos têm direito ao meio ambiente ecologicamente equilibrado, bem de uso comum do povo e essencial à sadia qualidade de vida" (BRASIL, 1988, p. 131).

Oportunamente, a seguir será feito um resgate da relação do Estado com o meio ambiente ao longo do tempo, dividindo-o em antes e após a Constituição de 1988.

\section{ANTERIOR A CONSTITUIÇÃO FEDERAL DE 1988}

Segundo Berté (2013, p. 145), no Primeiro Período Republicano ou Primeira República, que compreendeu de 1889 a 1930, foi um período essencialmente de degradação ambiental caracterizado pelo: "crescimento e a ampla propagação do setor agrícola, preponderância de extensos latifúndios e predomínio do cultivo de um só produto (monocultura)". Segundo o autor, esse quadro apenas sofreu mudanças em 1930, com Revolução de 1930 que culminou o início do Segundo Período Republicano ou República Nova, momento no qual: “inúmeras 
mudanças políticas, sociais e econômicas foram introduzidas no país, o que representou um estímulo ao desenvolvimento industrial, embora o apoio de fato às indústrias de base só tenha sido fomentado a partir de 1937, com a institucionalização do Estado Novo" (BERTÉ, 2013, p. 145).

Berté (2013) afirma que em 1946, com a redemocratização do país, ocorreu uma fase de desenvolvimento industrial, marcada por um programa de modernização industrial e urbana no Brasil, a qual adquiriu proporções maiores entre os anos 1951 e 1961:

É nesse cenário progressista que se insere o Governo de Juscelino Kubitschek (1956-1961), identificado pelo lema "Cinquenta anos de progresso em cinco anos de governo". No plano de desenvolvimento de seu governo, o chamado Plano de lMetas, constam como objetivos prioritários o desenvolvimento dos setores de energia, transporte, alimentação, indústria de base e educação (BERTÉ, 2013, p. 146).

O resultado desse cenário político e econômico foi a construção de estradas e de usinas hidrelétricas, criação da Superintendência do Desenvolvimento do Nordeste (Sudene), expansão do setor automobilístico e de eletrodomésticos e a criação da capital brasileira, Brasília, inaugurada em 1960. De acordo Berté (2013), esse período de mudanças no cenário brasileiro que se iniciou em 1960 e se estendeu até 1969, resultou em importantes conquistas na área ambiental com a edição das seguintes leis:

- O Estatuto da Terra, pela Lei Federal n. 4504/1964 (Brasil, 1964), cujo objetivo foi "a execução da Reforma Agrária e a promoção de Política Agrícola", no qual consta a possibilidade de desapropriação de áreas para a implantação de reservas florestais;

- Novo Código Florestal, pela Lei Federal n. 47771/1965 (Brasil, 1965b), que, entre outros aspectos, trata do desmatamento e da exploração das matas nativas;

- Política Nacional de Saneamento, que resultou de leis e decretos criados no período compreendido entre os anos de 1965 e 1969 e que, posteriormente, mais especificadamente em 1976, foi a base geradora do Programa Nacional de Saneamento (BERTÉ, 2013, p. 146, grifo do autor).

Nota-se, então, que o meio ambiente passou a entrar, de alguma forma, na agenda governamental a partir da década de 6o. Essa preocupação com a normatização de atividades relacionadas ao meio ambiente na década de 60, segundo Câmara e Oliveira (2011), também decorreu da influência de leis internacionais sobre o tema:

As manifestações protetivas avançaram das intenções manifestas no Direito Internacional para o âmbito interno dos mais diversos países. Assim, as Constituições posteriores a 1960 passaram a consagrá-las, impondo-se uma vigorosa atuação do Estado na esfera administrativa buscando conter a ocorrência de danos (CÂMARA; OLIVEIRA, 2011, p. 268). 
2 - Art. 172: A lei regulará, mediante prévio levantamento ecológico, o aproveitamento agrícola de terras sujeitas a intempéries e calamidades. O mau uso da terra impedirá o proprietário de receber incentivos e auxílios do Governo (BRASIL, 1967).
Dessa forma, nota-se que o Brasil a partir da década de 6o, seguindo uma tendência internacional, passou a ter uma maior atuação na esfera administrativa em relação à contenção de danos ambientais. Nesse contexto, segundo Muro Jr. (2016), a primeira Constituição brasileira a incluir o cuidado com o meio ambiente foi a de 1967 , alterada pela Emenda Constitucional n. 1/1969, a qual trouxe em seu Art. 172² de forma sutil, as primeiras preocupações com a questão ambiental: "muito singela, a Constituição de 1967 apenas mencionava a questão do levantamento ecológico e do aproveitamento agrícola em terras sujeitas a intempéries e a calamidades, sujeitando o proprietário rural à exclusão de incentivos estatais (MURO JR., 2016, p. 21)". Benjamin (2010, p. 109) enfatiza que "é fato que, antes de 1988, as Constituições brasileiras não estavam desenhadas de modo a acomodar os valores e as preocupações próprios de um paradigma jurídico ecológico". Assim, percebe-se que o meio ambiente passou a ser uma prioridade do Estado, apenas após a promulgação da Constituição de 1988, sendo que antes disso o tema era tratado apenas de forma superficial.

Porém, como lembra Benjamin (2010), esse período de "vazio constitucional", no que diz respeito ao meio ambiente, não significa que não houve ações para regulamentar as ações nocivas a ele: "a lacuna nas ordens constitucionais anteriores a 1988 não foi óbice sério e intransponível à regulamentação legal de controle das atividades nocivas ao ambiente ou, mais comumente, aos seus elementos" (BENJAMIN, 2010, p. 109). Isto é, por mais que as Constituições não trouxessem o meio ambiente como tutela do Estado, houve políticas públicas para regular as atividades que causassem danos ambientais como aquelas editadas na década de 60 trazidas por Berté (2013) anteriormente.

Entretanto, Muro Jr. (2016) considera que foi apenas na década de 70 que o Brasil passou a, de fato, a preocupar-se com as questões ambientais: "a mobilização do Estado brasileiro para normatizar o meio ambiente começou somente com a sua participação na Conferência de Estocolmo (1972), quando foi signatário do tratado internacional que levou o nome da cidade" (MURO JR., 2016, p. 21). Segundo Melo (2016), a Conferência de Estocolmo foi a primeira Conferência das Nações Unidas em escala mundial sobre as temáticas ambientais, da qual originou-se uma Declaração que, dentre outros princípios:

[...] encontra-se o conceito de responsabilidade para a proteção do meio ambiente e da conservação dos recursos naturais em relação às futuras gerações. É reconhecida a necessidade de introduzir a tutela ambiental nos programas de desenvolvimento e de adotar medidas integradas e coordenadas de administração dos recursos, de modo a assegurar que o desenvolvimento seja compatível com a necessidade de proteger e melhorar o ambiente (MELO, 2016, p. 242). 
Pode-se perceber que a partir da Conferência de Estocolmo, da qual o Brasil foi signatário, a questão do meio ambiente como tutela do Estado foi discutida em âmbito mundial, além da preocupação em proteger e preservar os recursos naturais para as futuras gerações.

Já na década de 80, foi editada a Lei n. 6.938, de 31 de agosto de 1981, a qual dispõe sobre a Política Nacional do Meio Ambiente (PNMA) e institui o Sistema Nacional do Meio Ambiente (SISNAMA), seus fins e mecanismos de formação e aplicação e dá outras providências. De acordo com Sirvinskas (2006, p. 103), o PNMA “trata-se da lei ambiental mais importante depois da Constituição Federal. Nela está traçada toda a sistemática necessária para a aplicação da política ambiental (conceitos básicos, objeto, princípios, objetivos, diretrizes, instrumentos, órgãos, responsabilidades objetiva, etc.)".

Portanto, mesmo que as Constituições anteriores a 1988 não tivessem dado um tratamento expresso de tutela ao meio ambiente, o Estado editou leis que, de alguma forma, contribuíram para a preservação do meio ambiente. Os atos do governo referentes à questão ambiental iniciaram-se na década de 6o, de forma sutil, com a edição de algumas leis para normatizar algumas atividades com potencial degradante ao meio ambiente, tais como o Estatuto da Terra (1964), Novo Código Florestal (1965) e a Política Nacional de Saneamento (1965 a 1969) e com a Constituição de 1967, a qual tratou de forma superficial a questão ambiental. Sendo, então, apenas nas décadas de 70 e 80 quando despontou a preocupação com a tutela do meio ambiente a partir da participação do Brasil na Conferência de Estocolmo e com a criação do PNMA, em 1981, quando "ensaiou-se o primeiro passo em direção a um paradigma jurídico-econômico que holisticamente tratasse e não maltratasse a terra, seus arvoredos e os processos ecológicos essências a elas associados" (BENJAMIN, 2010, p. 77).

\section{POSTERIOR A CONSTITUIÇÃO FEDERAL DE 1988}

Foi a partir da promulgação da Constituição Federal de 1988 que o meio ambiente passou a ser tratado de forma preponderante: "com o advento da Constituição de 1988 ocorre um avanço significativo: o direito ao meio ambiente ecologicamente equilibrado é elevado a direito fundamental" (PIOVESAN; FACHIN, 2011, p. 36). Isso está preconizado no Art. 225, da Constituição Federal: "todos têm direito ao meio ambiente ecologicamente equilibrado, bem de uso comum do povo e essencial à sadia qualidade de vida, impondo-se ao poder público e à coletividade o dever de defendê-lo e preservá-lo para as presentes e futuras gerações (BRASIL, 1988, p. 2).

Assim, a partir da Constituição de 1988, o meio ambiente foi elevado a direito fundamental, trazendo o Estado para si a tutela do meio ambiente, porém não cabendo apenas a este o dever de protegê-lo e preservá-lo, mas também a todos os indivíduos. Segundo Benjamin (2010, p. 89), a constitucionalização do meio ambiente trouxe consigo “benefícios variados e de diversas ordens, bens palpáveis, pelo impacto 
real que podem ter na (re) organização do relacionamento do ser humano com a natureza". O autor elenca seis benefícios substantivos da constitucionalização do meio ambiente, isto é, que reorganizam a estrutura profunda de direitos e deveres: 1 ) estabelecimento de um dever constitucional genérico de não degradar, base do regime de explorabilidade limitada e condicionada; 2) ecologização da propriedade e da sua função social; 3) a proteção ambiental como direito fundamental; 4) legitimação constitucional da função estatal reguladora; 5) redução da discricionariedade administrativa e 6) ampliação da participação pública.

Outro fato importante foi a Conferência das Nações Unidas sobre o ambiente e desenvolvimento (Unced) ocorrida no Rio de Janeiro, em 1992, conhecida por ECO 92. No evento, foram aprovados três documentos importantes: a Declaração do Rio sobre o ambiente e o desenvolvimento, a Declaração sobre "Princípios das florestas" e a Agenda 21, além disso foram adotadas duas importantes Convenções: a Convenção sobre a biodiversidade e a Convenção sobre as mudanças climáticas. Segundo Melo (2016, p. 246), esses documentos "definem uma visão conjunta e complexa dos temas ligados à sustentabilidade e ao desenvolvimento e que é ainda hoje atual para as ações internacionais relativas a esses temas".

Sendo assim, é nítida a mudança de postura do Estado perante o meio ambiente após a promulgação da Constituição de 1988, quando o mesmo adota o papel de tutor do meio ambiente e coloca um meio ambiente saudável e equilibrado como um direito e dever da coletividade. A partir dessa nova forma de tratar o meio ambiente, surge uma nova visão de Estado, conhecida como Estado de Direito Ambiental ou Socioambiental.

\section{TERCEIRA DIMENSÃO DE DIREITOS FUNDAMENTAIS: MEIO AMBIENTE FINALMENTE ENTRA EM FOCO?}

Os direitos fundamentais, ao longo do tempo, foram obtendo enfoques distintos nas Constituições brasileiras, refletindo o que a sociedade de cada momento vivenciara. E para melhor compreender essa evolução dos direitos fundamentais, eles foram identificados em dimensões. Embora haja a discussão em relação à quantia e ao conteúdo de dimensões que se teria até o atual momento, "verifica-se crescente convergência de opiniões no que concerne ao conteúdo pelo menos das três primeiras dimensões dos direitos fundamentais" (SARLET, 2017, p. 312).

Desse modo, a primeira geração, fruto do pensamento liberal burguês do século XVIII, seria marcada por "direitos de resistência ou de oposição perante o Estado", sendo marcados pelos direitos à vida, à liberdade, à propriedade e igualdade perante à lei, dentre outros, todos com enfoque na autonomia do indivíduo, caracterizando, assim, um Estado Liberal (SARLET, 2017).

Já a chamada segunda dimensão, motivada pelos graves pro- 
blemas sociais e econômicos e pelo impacto da industrialização, seria caracterizada por uma dimensão positiva, "uma vez que se cuida não mais de evitar a intervenção do Estado na esfera da liberdade individual, mas, sim, na lapidar de Celso Lafer, de propiciar um 'direito de participar do bem-estar'" (SARLET, 2017, p. 315). Nessa dimensão estão os direitos a prestações sociais e também às "liberdades sociais", passando o enfoque da autonomia do sujeito para o bem-estar social, caracterizando, então, um Estado Social.

Por último, os direitos fundamentais de terceira dimensão são marcados por um deslocamento do foco "da figura homem-indivíduo como seu titular, destinando-se à proteção de grupos humanos (povo, nação), caracterizando-se, consequentemente, como direitos de titularidade transidividual (coletiva ou difusa)" (SARLET, 2017, p. 316). Dentre os direitos fundamentais de terceira dimensão, estão os direitos à paz, à autoderminação dos povos, ao desenvolvimento, ao meio ambiente e qualidade de vida, bem como o direito à conservação e utilização do patrimônio histórico e cultural e o direito à comunicação. Ou seja, o foco passa a não ser mais o indivíduo, mas a coletividade.

Foi então, a partir da Constituição Federal de 1988, que o meio ambiente ganhou status de direito fundamental, passando a ser um direito de todos poder contar com um meio ambiente sadio e equilibrado. Porém, ao mesmo tempo, a sua defesa e preservação passou a ser, também, um dever do poder público e da coletividade. É o que preconiza o Art. 225: "todos têm direito ao meio ambiente ecologicamente equilibrado, bem de uso comum do povo e essencial à sadia qualidade de vida, impondo-se ao poder público e à coletividade o dever de defendê-lo e preservá-lo para às presentes e futuras gerações" (BRASIL, 1988, p. 2). Essa maior preocupação com o meio ambiente instaurada pela Constituição Federal de 1988, tratando-o como um direito fundamental e atribuindo ao poder público e a coletividade o dever de proteção e preservação, refletindo uma demanda da sociedade, fez com que muitos autores denominassem de Estado de Direito Ambiental.

De acordo com Leite (2010, p.169), “o Estado de Direito do Ambiente é uma construção teórica que se projeta no mundo real ainda como devir". Isto é, consiste em uma teoria que ainda está em processo de materialização, na qual o Estado projeta no meio ambiente um papel preponderante em relação à mercantilização. Além disso, projeta na coletividade o dever e o direito de preservá-lo, como afirma Leite (2010), "o Estado Ambiental é um quadro de mais sociedade, mais direitos e deveres individuais e mais direitos e deveres coletivos e menos Estado e menos mercantilização (idem)". Assim, nesse modelo de Estado os direitos e deveres da sociedade são maximizados, enquanto que a presença do Estado e a mercantilização são minimizados, para tanto sendo imprescindível um maior engajamento da sociedade, principalmente, nas causas ambientais.

Embora tenha essa preocupação com mais sociedade e menos Estado, o debate não gira em torno do público em detrimento do pri- 
vado ou vice-versa, mas em torno de uma autonomia do indivíduo e da coletividade perante a mercantilização: "nesse novo contexto, não é prioritário o doseamento entre público e privado, mas sim o reforço da autonomia (logo, dos direitos e das responsabilidades) individual e social frente à mercantilização e à burocratização" (PUREZA; FRADE, 1998, p. 8-9). Portanto, o Estado de Direito Ambiental tem como figuras centrais o indivíduo crítico e autônomo e o meio ambiente, cabendo ao Estado à tarefa de instigar essa consciência ecológica na coletividade, o que não significa que o Estado não detenha a tutela do meio ambiente, significa apenas que ele que abra mais espaço para a sociedade atuar conjuntamente na proteção e preservação do ambiente.

Nunes Júnior (2005, p. 3) faz uma diferenciação das finalidades de cada modelo de Estado para, então, esclarecer o objetivo do Estado Ambiental: "a finalidade do Estado Liberal é a liberdade, e a do Estado Social é a igualdade. Já o Estado Ambiental tem uma finalidade mais ampla: a solidariedade (centrada em valores que perpassam a esfera individualista própria do Estado Liberal)". Desse modo, o Estado de Direito Ambiental tem como finalidade a solidariedade, além de ter "valor como construção teórica e mérito como proposta de exploração de outras possibilidades que se apartam da realidade para compor novas combinações daquilo que existe" (LEITE, 2010, p. 169).

Para Canotilho (1999) para um Estado atribuir a condição de ambiental, ele precisa priorizar duas dimensões jurídico-políticas importantes:

A primeira é a obrigação de o Estado, em cooperação com outros Estados e cidadãos ou grupos da sociedade civil, promover políticas públicas (econômicas, educativas, de ordenamento) pautadas pelas exigências da sustentabilidade ecológica. A segunda relaciona-se com o dever de adopção de comportamentos públicos e privados amigos do ambiente de forma a dar expressão concreta à assumpção da responsabilidade dos poderes públicos perante as gerações futuras. [...] A afirmação desta nova dimensão do Estado pressupõe o diálogo democrático, exige instrumentos de participação, postula o princípio da cooperação com a sociedade civil. O Estado de ambiente constrói-se democraticamente de baixo para cima; não se dita em termos iluminísticos e autoritários de cima para baixo (CANOTILHO, 1999, p. 17).

Desse modo, tem-se que para um Estado "ser ambiental" ele deve estar voltado para a criação de políticas públicas relacionadas à economia, educação e de ordenamento pautadas pela exigência da sustentabilidade ecológica, além de adotar comportamentos que não agridam e venham a degradar o meio ambiente. Não obstante, essa concepção de Estado deve privilegiar o diálogo democrático com a sociedade, ou seja, o Estado de Direito Ambiental deve ser uma construção de baixo para cima, construída a partir da participação popular.

Mais além, Sarlet e Fenterseifer (2010) defendem ser mais adequa- 
do que se fale em um Estado Socioambiental de Direito, pois acreditam que o Estado deve ser, além de ambiental, também social: "trata-se, em verdade, de agregar num mesmo projeto político-jurídico, tanto as conquistas do Estado Liberal e do Estado Social, quanto às exigências e valores que dizem respeito ao assim designado Estado Socioambiental de Direito contemporâneo" (SARLET; FEINSTERSEIFER, 2016, p. 13). Os autores afirmam que, antes de enfrentar os problemas ambientais e buscar um desenvolvimento sustentável, é primordial que os indivíduos tenham seus direitos sociais básicos atendidos, tais como educação, saúde básica, renda mínima, pois, caso contrário, isso possivelmente acaba gerando degradação ambiental.

Por isso a importância de acrescentar o termo Sócio ao Estado de Direito Ambiental, pressupondo um Estado que garanta os direitos sociais básicos para que os pressupostos do Estado de Direito Ambiental possam ser atingidos. Por essa razão, Sarlet e Feinsterseifer (2016, p. 15) afirmam que a qualidade ambiental deve ser acrescentada ao rol de direitos garantidores de um mínimo existencial, tais como moradia digna, saúde básica, educação, visando a "garantia de uma existência humana digna e saudável, especialmente no que diz com a construção da noção de um bem-estar existencial que tome em conta também a qualidade do ambiente". Isto é, a qualidade do meio ambiente deve integrar o princípio da dignidade da pessoa humana ao lado da dimensão social, histórico-cultural, etc., pois o "desfrute de um bem-estar ambiental, ou seja, de uma vida saudável com qualidade ambiental, o que se apresenta como indispensável ao pleno desenvolvimento da pessoa e ao desenvolvimento humano".

Dessa forma, considerando que um meio ambiente sadio seja um direito e um dever de todos e que o mesmo deva ser acrescentado à lista de garantidores de um mínimo existencial, ao lado daqueles mínimos existenciais que são essenciais para que se tenha a dignidade da pessoa humana, não é exagero afirmar que se vive um grande desafio na medida em que se tenta pôr em prática uma construção teórica que pressupõe, além dos direitos sociais que há tanto se busca, mais direitos ambientais que também se constitui em um paradigma da modernidade.

\section{POLÍTICA NACIONAL DE RESÍDUOS SÓLIDOS: MEIO AMBIENTE COMO DIREITO FUNDAMENTAL?}

Viu-se, então, que atualmente se vive uma terceira dimensão de direitos fundamentais, na qual o meio ambiente ganha uma preponderância nunca observada, sendo elevado a direito fundamental e integrador do rol de mínimos existenciais garantidores da dignidade da pessoa humana. Também se viu que sua concretização não parece simples, pois envolvem interesses antagônicos de setores da sociedade, indo contra a ideia de direitos coletivos preconizados pelo Estado Socioambiental de Direito. 
Para tentar ilustrar essa problemática, traz-se à tona a Lei 12.305/2010, a qual institui a Política Nacional dos Resíduos Sólidos (PNRS) e dispõe sobre seus princípios, objetivos e instrumentos, bem como sobre as diretrizes relativas à gestão integrada de resíduos sólidos. Por gestão integrada de resíduos sólidos entende-se o "conjunto de ações voltadas para a busca de soluções para os resíduos sólidos, de forma a considerar as dimensões política, ambiental, cultural e social, com controle social e sob a premissa do desenvolvimento sustentável" (BRASIL, 2010, p. 2).

Tal Política é considerada um marco nas políticas ambientais na medida em que exige dos estados, distrito federal e municípios a criação de seus respectivos planos de gerenciamento integrados de resíduos sólidos sob pena de não repasse de verbas da União referentes a tal temática. Além disso, estabelece nos Art. 15 e no Art. 17, inciso V, que entre os conteúdos abordados planos de gerenciamento de resíduos sólidos da União e dos estados para os próximos vinte anos deve haver "metas para a eliminação e recuperação de lixões, associadas à inclusão social e à emancipação econômica de catadores de materiais reutilizáveis e recicláveis" (BRASIL, 2010, p. 7). 


\section{Revista de Gestão Pública}

PRÁTICAS E DESAFIOS ISSN: 2177-1243

Os objetivos da PNRS estão expostos no quadro abaixo:

QuAdro 1 - Objetivos da Política Nacional de Resíduos Sólidos

\begin{tabular}{|c|c|}
\hline \multirow{17}{*}{$\begin{array}{l}\text { Objetivos da Política } \\
\text { Nacional de Resíduos } \\
\text { Sólidos }\end{array}$} & I - Proteção da saúde pública e da qualidade ambiental; \\
\hline & $\begin{array}{l}\text { II- Não geração, redução, reutilização, reciclagem e tratamento dos resíduos sólidos, bem como } \\
\text { disposição final ambientalmente adequada dos rejeitos; }\end{array}$ \\
\hline & III - Estímulo a adoção de padrões sustentáveis de produção e consumo de bens e serviços; \\
\hline & $\begin{array}{l}\text { IV - Adoção, desenvolvimento e aprimoramento de tecnologias limpas como forma de minimizar } \\
\text { impactos ambientais; }\end{array}$ \\
\hline & V - Redução do volume e da periculosidade dos resíduos perigosos; \\
\hline & $\begin{array}{l}\text { VI - Incentivo à indústria da reciclagem, tendo em vista fomentar o uso de matérias-primas e insumos } \\
\text { derivados de materiais recicláveis e reciclados; }\end{array}$ \\
\hline & VII - Gestão integrada de resíduos sólidos; \\
\hline & $\begin{array}{l}\text { VIII - Articulação entre as diferentes esferas do poder público, e destas com o setor empresarial, com } \\
\text { vistas a cooperação técnica e financeira para a gestão integrada de resíduos sólidos; }\end{array}$ \\
\hline & IX - Capacitação técnica continuada na área dos resíduos sólidos; \\
\hline & $\begin{array}{l}\text { X- Regularidade, continuidade, funcionalidade e universalização da prestação dos serviços públicos } \\
\text { de limpeza urbana e de manejo de resíduos sólidos, com adoção de mecanismos que assegurem } \\
\text { a recuperação dos custos dos serviços prestados, como forma de garantir sua sustentabilidade } \\
\text { operacional e financeira, observada a Lei n. } 11.445 \text {, de } 2007 \text {; }\end{array}$ \\
\hline & XI - Prioridade, nas aquisições e contratações governamentais, para: \\
\hline & a) produtos reciclados e recicláveis; \\
\hline & $\begin{array}{l}\text { b) bens, serviços e obras que considerem critérios compatíveis com padrões de consumo social e } \\
\text { ambientalmente sustentáveis; }\end{array}$ \\
\hline & $\begin{array}{l}\text { XII - Integração dos catadores de materiais reutilizáveis e recicláveis nas ações que envolvam a } \\
\text { responsabilidade compartilhada pelo ciclo de vida dos produtos; }\end{array}$ \\
\hline & XIII - Estímulo à implementação da avaliação do ciclo de vida do produto; \\
\hline & $\begin{array}{l}\text { XIV - Incentivo ao desenvolvimento de sistemas de gestão ambiental e empresarial voltados para a } \\
\text { melhoria dos processos produtivos e ao aproveitamento dos resíduos sólidos, incluídos a recuperação } \\
\text { e o aproveitamento energético; }\end{array}$ \\
\hline & XV - Estímulo à rotulagem e ao consumo sustentável. \\
\hline
\end{tabular}


Essa proposta estabelecida pela PNRS consiste num importante passo rumo à consolidação de um Estado Socioambiental na medida em que procura resolver ou, pelo menos, amenizar um problema ambiental que há muito preocupa: os resíduos sólidos. Exigindo dos estados e municípios a desativação de lixões a céu aberto, bem como a criação de planos de gerenciamento de resíduos sólidos, a PNRS aborda um problema ambiental que assola a sociedade moderna, mas, ao mesmo tempo, também trás a preocupação com o social na medida em que coloca os catadores de materiais recicláveis como protagonistas dessa mudança, exigindo que os resíduos sólidos sejam geradores de renda e cidadania para os mesmos.

De acordo com levantamento realizado pelo Meio Ambiente, baseado em uma consulta anual realizada junto aos órgãos estaduais, em 2017, pouco mais da metade dos municípios, 54,8\%, possuíam Plano Integrado de Resíduos Sólidos. Também foi constatado que a presença do plano tende a ser maior em municípios com maior porte populacional, sendo que os municípios com mais de 50.000 habitantes ficaram com um índice de $83,3 \%$, enquanto que os municípios de 5.001 a 10.000 habitantes apresentaram um índice de $49,1 \%$ de presença do plano (MINISTÉRIO DO MEIO AMBIENTE, 2018, p. 1).

$O$ fato é que a implementação dessas medidas socioambientais cabem aos municípios, os quais, na grande maioria, enfrentam uma série de problemas que dificultam pôr em prática as ações previstas na PNRS. Em 2012, uma pesquisa dirigida pela Confederação Nacional de Municípios (CNM) já apontava que quase $86 \%$ dos municípios estão em situação fiscal difícil ou deficitária. Dentre as principais causas apontadas pela pesquisa estavam: a queda na receita de transferências da União em razão tanto da fraca atividade econômica quanto da política de desoneração do Governo Federal; o enorme volume acumulado de restos a pagar da União devido a municípios; a renúncia fiscal relativa a não resolução da Guerra Fiscal do ICMS, dentre outros (CONFEDERAÇÃO NACIONAL DOS MUNICÍPIOS, 2013, p. 172).

Passados, pouco mais de oito anos da edição da Lei 12.305/2010, o prazo inicial para a desativação dos lixões a céu aberto, previsto para 2014, já foi postergado várias vezes. Sabe-se que a construção de aterros sanitários, a qual seria a opção mais adequada de dispor os resíduos sólidos, exige um considerável aporte financeiro dos municípios. Como alternativa, a própria PNRS sugere a construção de consórcios entre os entes federados "com vistas à elevação das escalas de aproveitamento e à redução dos custos envolvidos" (BRASIL, 2010, p. 5). Contudo, essa opção que os municípios teriam esbarra em algumas dificuldades, tais como "deficiência na qualificação dos gestores públicos nessa área, poucos profissionais capacitados e habilitados para trabalhar com consórcios públicos e dificuldade de convencer os gestores públicos a aderirem ao consórcio" (PEIXOTO, 2008 apud MAIELLO; BRITTO; VALLE, 2018, p. 24). Frente a isso, a alternativa encontrada pelos municípios com menor aporte populacional é enviar os seus resíduos sólidos para 
aterros sanitários particulares, resultando em um elevado custo anual para os cofres municipais ou permanecer depositando seus resíduos sólidos em lixões a céu aberto. No caso desses municípios, onde estaria o direito fundamental a um meio ambiente sadio e equilibrado? $\mathrm{O}$ Estado está prestando apoio para que os municípios desenvolvam seus planos de gerenciamento e os executem? O Estado está contribuindo, de fato, para melhorar a qualidade ambiental da coletividade ou a sua atuação apenas se restringe a criar leis e punir os municípios pelo não cumprimento das mesmas?

\section{- desAFIO dA CONSTRUÇÃo do ESTADO DE DIREITO AMBIENTAL}

Embora a proposta da construção de um Estado de Direito Ambiental traga consigo a esperança de uma coletividade consciente, crítica e predisposta a preservar o meio ambiente, ela constitui-se em um grande desafio na medida em que a preservação dos recursos ambientais é posta frente ao desenvolvimento econômico:

Diante de um mundo marcado por desigualdades sociais e pela degradação em escala planetária, construir um Estado de Direito Ambiental parece ser uma tarefa de difícil consecução, porque se sabe que os recursos ambientais são finitos e antagônicos com a produção de capital e consumo existentes (LEITE, 2010, p. 169).

Isso pode ser ilustrado através da PNRS, que após mais de oito anos de sua existência, ainda esbarra em muitas dificuldades. Frente a isso, surge o seguinte questionamento: como construir um Estado Sociambiental de Direito? Está faltando consciência crítica da coletividade? Educação ambiental? Ou informação, que é peça chave das duas primeiras? Ou, como afirma Canotilho (1999), está faltando comportamentos do Estado amigos do meio ambiente?

Para Leite (2010), na prática, a execução de um Estado de Direito Ambiental "só será possível a partir da tomada de consciência global da crise ambiental, em face das exigências, sob pena de esgotamento irreversível dos recursos ambientais, de uma cidadania moderna, informada e pró-ativa" (LEITE, 2010, p. 181). Percebe-se, então, que um primeiro e primordial passo rumo ao Estado de Direito Ambiental é a ciência da coletividade em relação à gravidade dos problemas ambientais dos quais estamos diante e que, caso nenhuma postura seja tomada, há o risco iminente de um esgotamento dos recursos ambientais, sendo isso um requisito de uma cidadania moderna, informada e pró-ativa.

Porém, Freitas (2010, p. 20) assinala que essa consciência da coletividade em relação ao seu papel pró-ativo na questão ambiental nem sempre existe. Isso resulta que "na realidade, ao Poder Público que cabe o papel principal na tutela do ambiente sadio. De sua ação adequada e responsável deverá resultar, inclusive, efeito pedagógico ao atuar no sentido do fortalecimento da consciência ecológica do povo". Assim, 
embora a responsabilidade sobre o meio ambiente seja compartilhada no Estado de Direito Ambiental, na maioria das vezes, pela falta de consciência, a responsabilidade principal acaba recaindo apenas no Estado, cabendo a ele servir de exemplo, numa tentativa de despertar o interesse e a consciência da coletividade.

No caso da PNRS, a responsabilidade está recaindo apenas no Estado? Caso esteja, está acontecendo ações por parte deste para instigar a consciência coletiva, pois essa é condição essencial para a participação popular, que consiste em outro passo importante rumo à concretização de um Estado Ambiental.

Nesse sentido, Canotilho (1999, p. 17) afirma que essa "nova dimensão do Estado pressupõe o diálogo democrático, exige instrumentos de participação, postula o princípio da cooperação com a sociedade civil". Para Melo (2016, p. 250) "quando se pensa na concretização destes direitos, princípios e regras de proteção, que a questão se torna muito mais complexa". Segundo a autora, o desafio é:

[...] neste cenário de abertura da participação política e administrativa a novos sujeitos, surge o interrogativo de como estimular e garantir, na prática cotidiana da gestão dos problemas da comunidade, a participação do maior número de cidadãos e criar condições para a otimização dos resultados - e, ao mesmo tempo, neutralizar os riscos de decisões tecnocráticas e/ou uma instrumentalização dos interesses privados dos lobbies (MELO, 2016, p. 251).

Entretanto, apesar de ser uma tarefa complexa por envolver, de um lado, a preocupação com a sustentabilidade e, de outro, o interesse mercadológico, a participação popular deve ser estimulada.

De acordo com Fiorillo (2013), a participação constitui um dos elementos do Estado Social de Direito, ou Estado Ambiental de Direito, e para que ela seja efetivada são necessários dois elementos fundamentais que devem ser trabalhados em conjunto: a informação e a educação ambiental. Segundo o autor, a informação ambiental encontra respaldo legal nos Arts. 6으 $\S 3^{\circ}$, e 10 da Política Nacional do Meio Ambiente e a educação ambiental no Art. 225, § 1, VI, da Constituição Federal: "alguns princípios do direito ambiental constitucional se interpenetram, de modo a estabelecer uma interdependência. [...] a educação ambiental é efetivada mediante a informação ambiental, que é expressamente abraçada pela Constituição" (FIORILLO, 2013, p. 127).

Para Fiorillo (2013), educar ambientalmente consiste em:

a) reduzir os custos ambientais, à medida que a população atuará como guardiã do meio ambiente; b) efetivar o princípio da preservação; c) fixar a ideia de consciência ecológica, que buscará sempre a utilização de tecnologias limpas; d) incentivar a realização do princípio da solidariedade, no exato sentido que perceberá que o meio ambiente é único, indivisível e de titulares indetermináveis, devendo ser justa e distributivamente acessível a todos; e) efetivar o princípio da participação, entre outras finalidades (FIORILLO, 2013, p. 128-129). 
Desse modo, o acesso a informações é condição essencial para que aconteça a educação ambiental e, consequentemente, instigue a consciência crítica nos cidadãos, e os dois elementos juntos essenciais para a efetivação da participação popular. Em relação à disponibilização de informações, Manzano (2008) afirma:

El acesso a la información relevante es el elemento fundamental para permitir una participación realmente eficiente. Sin embargo, a pesar del consenso existente a la hora de vincular la eficácia de la participación a la existência de um flujo de información suficiente que garantisse que los ciudadanos puedan ser conscientes de como uma decisión puede afectar a sus interesses, la información a partir de la que puede funsarse la actividad participativa es, em mucha ocasiones, insuficiente, dificilmente acessible o sencillamente incompresible, de manera que el ciudadano deja estar em condicionas de participar de manera efectiva em el procedimento de toma de decisiones (MANZANO, 2008, p. 134-135).

Desse modo, para a participação popular ser efetiva é necessário que haja a disponibilização de informações, entretanto o que comumente acontece é que as informações disponibilizadas não são suficientes, de difícil acesso ou incompreensíveis para que o cidadão tenha condições de participar das decisões. Por isso, não é suficiente apenas disponibilizar informações, mas, sim, disponibilizar informações claras, suficientes e acessíveis ao entendimento de todos.

Além disso, Melo (2012) defende ser necessária uma mudança de hábitos cotidianos dos governos e dos cidadãos:

[...] iniciativas que podem ser mais simples ou ambiciosas, porém igualmente necessárias, visto que uma melhor qualidade de vida no planeta envolve ações que vão desde a participação nos Summits e nas Conferências internacionais para o meio ambiente, até a decisão de reduzir as luzes acesas no escritório ou em casa, reduzir a temperatura do ar condicionado, optar por um carro menos elegante mas mais econômico ou mesmo escolher a bicicleta, separar o lixo, reusar, reciclar. Trata-se de transformações necessárias em todos os níveis, desde a decisão pelo plano energético do país, o urbanismo da cidade, o transporte usado para ir ao trabalho, a merenda da escola, até as escolhas de consumo e do tempo livre, que podem privilegiar atividades mais saudáveis e um modelo de turismo ambientalmente sustentável (MELO, 2012, p. 165).

Verifica-se que quando se fala em mudanças de hábitos, não se refere apenas a grandes mudanças ou acontecimentos, mas também a atitudes corriqueiras do dia a dia que devem virar hábito, como economizar energia elétrica e separar, reduzir e reciclar o próprio lixo, que estão ao alcance da maioria dos indivíduos. Pequenos e grandes atos que devem partir de todos os níveis, desde o cidadão comum até os 
altos escalões governamentais.

Desse modo, percebe-se que materializar o Estado de Direito Ambiental constitui-se um grande desafio e que para torná-lo uma realidade um primeiro passo consiste na tríade: acesso à informação, consciência coletiva e participação popular, ficando visível que a informação é uma peça central para a efetivação de tal proposta, pois é a partir da qual se efetiva os demais requisitos para um Estado realmente Ambiental.

\section{CONSIDERAÇÕES FINAIS}

Foi a partir da década de 60 que o Estado passou a editar leis voltadas ao meio ambiente, porém elas tinham por objetivo apenas normatizar algumas atividades com potencial degradante ao meio ambiente. Uma maior preocupação ambiental pode ser percebida a partir da década de 70, com a participação do Brasil, como signatário, da Conferência de Estocolmo, em 1972 e com a edição do Plano Nacional do Meio Ambiente, em 1981, o qual até hoje se constitui em um importante instrumento balizador das atividades ambientais.

A Constituição de 1988 pode ser considerada um divisor de águas no que diz respeito à preocupação ambiental, pois a partir de sua promulgação um meio ambiente sadio e equilibrado passou a ser um direito fundamental, cabendo ao Estado, juntamente com a coletividade, a sua tutela e o dever de preservá-lo para as futuras gerações. A partir de então, fala-se em um Estado de Direito Ambiental, o qual seria um Estado e uma coletividade preocupados e engajados com a proteção e o uso sustentável dos recursos naturais perante a mercantilização. Ou, mais além, fala-se em um Estado Socioambiental de Direito, que traria além da preocupação ambiental, também uma preocupação com o social. Trata-se de uma construção teórica e sua concretização passa a ser, mais do que nunca, o grande desafio do século XXI, na medida em que os recursos naturais são finitos enquanto que a exploração dos mesmos cresce exponencialmente juntamente com o aumento do consumismo.

Percebeu-se que para um Estado Socioambiental ser efetivado são necessários três elementos primordiais: informação clara, suficiente e acessível, conscientização coletiva e participação popular, podendo ser considerado um tripé ao passo que todos eles estão inter-relacionados. Sendo assim, a caminhada rumo ao Estado Ambiental deve partir do próprio Estado com a disponibilização de informações claras para que todos tenham acesso e possam compreendê-las para, então, instigar a criação de uma consciência coletiva sobre a situação preocupante e urgente que os recursos naturais precisam ser preservados para que os mesmos não se esgotem. Esses dois fatores são imprescindíveis para que haja uma participação efetiva da população nas causas ambientais somado a isso a oferta de instrumentos de participação pelo Estado.

Porém, a prática parece não ser tão simples assim. Analisando a PNRS, constatou-se que a construção de um Estado Socioambiental ainda encontra muitas dificuldades, embora não se possa negar que 
está havendo evolução. Assim, podendo-se dizer que o direito a um meio ambiente sadio e equilibrado é um direito fundamental que ainda não é acessível a todos, já quase metade dos municípios brasileiros ainda depositam seus resíduos sólidos em lugares inapropriados, colocando em risco a saúde dos seus cidadãos.

Após oito anos de vigência, o objetivo principal da PNRS, a construção do plano de gerenciamento de resíduos sólidos e a consequente desativação dos lixões a céu aberto, não foi atingido em quase metade dos municípios brasileiros, sendo que a causa maior desse cenário é atribuída à escassez de recursos financeiros. Porém, a construção de consórcios públicos, que seria uma das opções mais viáveis para sanar essa questão e que é sugerida pela própria PNRS, não está acontecendo com a frequência esperada em decorrência de dificuldades como: deficiência na qualificação dos gestores públicos nessa área, poucos profissionais capacitados e habilitados para trabalhar com consórcios públicos e dificuldade de convencer os gestores públicos a aderirem ao consórcio. Dificuldades que poderiam ser reduzidas através da disponibilização de informação e treinamento para os gestores públicos municipais, os quais poderiam estar mais aptos e seguros para firmar consórcios públicos e, então, encontrar soluções ecologicamente corretas que não esbarrem na dificuldade financeira.

Em relação à consciência ambiental, é importante frisar que ela deve acontecer em todos os níveis, desde o cidadão comum até aqueles dotados de poder decisório, pois caso esses últimos não a tenham, não haverá a construção de políticas públicas sustentáveis e não haverá o que preconiza Canotilho (1999), que é comportamentos do Estado amigos do meio ambiente. Nesse sentido, percebeu-se que o Estado foi pontual em estabelecer exigências para os municípios e puni-los pelo não cumprimento das mesmas, porém não pode ser observado o mesmo em relação ao apoio prestado a estes.

Não obstante, a consciência coletiva implica também em mudança de comportamento, tornando habituais ações como apagar as luzes quando não estão sendo usadas e separar, reduzir e reciclar o próprio lixo, as quais estão ao alcance da maioria dos indivíduos. Pequenos atos que, coletivamente, tornam-se grandes ações. Ter atitudes sustentáveis requer a criação de uma cultura sustentável a qual é criada através da educação ambiental, que também cabe ao Estado promovê-la. Uma vez conscientizados, os cidadãos estarão mais aptos a participar das políticas públicas ambientais.

Por mais complexa que seja, ainda sim é possível a construção de um Estado Socioambiental de Direito e para a sua efetivação envolve um processo lento que envolve acesso à informação, consciência ecológica e participação popular, conscientização, educação e participação de cidadãos e governantes. Caso esses elementos não aconteçam tanto no nível dos cidadãos, quanto no nível decisório, o meio ambiente não será um direito fundamental acessível a todos. 


\section{REFERÊNCIAS}

BECK, Ulrich. Sociedade de risco: rumo a uma outra modernidade. 2. ed. São Paulo: 34, 2011.

BENJAMIN, Antônio Herman. Constitucionalização do ambiente e ecologização da constituição brasileira. In: CANOTILHO, José Joaquim Gomes; LEITE, José Rubens Morato (Orgs.). Direito constitucional ambiental brasileiro. 3. ed. rev. São Paulo: Saraiva, 2010.

BERTÉ, Rodrigo. Gestão socioambiental no Brasil: uma análise ecocêntrica. Curitiba: Intersaberes, 2013.

BRASIL. Constituição da República Federativa do Brasil de 1967, de 24 de janeiro de 1967. Brasília, 1967. Disponível em: < http://www.planalto.gov.br/CCivil_03/Constituicao/ Constituicao67.htm>. Acesso em: 10 ago. 2018.

Lei 6.938, de 31 de agosto de 1981. Dispõe sobre a Política Nacional do Meio Ambiente, seus fins e mecanismos de formulação e aplicação, e dá outras providências. Brasil, 1981. Disponível em: <http://www.planalto.gov.br/ ccivil_03/Leis/L6938.htm.>. Acesso em: 8 agos. 2018.

\section{Constituição da República Federativa do Brasil}

de 1988, de o5 de outubro de 1988. Brasília, 1988. Disponível em: < <http://forumeja.org.br/sites/forumeja.org.br/files/ constituicaofederalig88.pdf > . Acesso em: 14 set. 2017.

Lei 12.305, de 02 de agosto de 2010. Institui a Política Nacional de Resíduos Sólidos. Brasília, 2010. Disponível em: http://www.mma.gov.br/port/conama/ legiabre.cfm?codlegi=636 Acesso em: 16 jan. 2019.

CANOTILHO, Joaquim José Gomes. Estado de Direito. Lisboa: Fundação Mário Soares, 1999.

CÂMARA, Luiz Antônio; OLIVEIRA, Cristina. Breves impressões sobre a legitimidade da tutela penal do meio ambiente. In: GALLI, Alessandra (Coord.). Direito socioambiental: homenagem a Vladimir Passos. Curitiba: Juruá, 2011.

CONFEDERAÇÃO NACIONAL DOS MUNICÍPIOS. Pesquisa sobre a situação financeira dos municípios em final de mandado. Estudos técnicos CNM, v. 5, Brasília: CNM, 2013. Disponível em: https://www.cnm.org.br/cms/biblioteca/Estudos\%20Tecnicos\%2O -\%20Volume\%205\%20(2013).pdf Acesso em: 07 jan. 2019.

FIORILLO, Celso Antonio Pacheco. Curso de direito 
ambiental brasileiro. 14. ed. São Paulo: Saraiva, 2013.

FREITAS, Vladmir Passos de. Direito administrativo e meio ambiente. 4. ed. Curitiba: Juruá, 2010.

LEITE, José Rubens Morato. Sociedade de risco e Estado. In: CANOTILHO, José Joaquim Gomes; LEITE, José Rubens Morato (Orgs.). Direito constitucional ambiental brasileiro. 3. ed. rev. São Paulo: Saraiva, 2010.

MAIELLO, Antonella; BRITTO, Ana Lucia Nogueira de Paiva; VALLE, Tatiana Freitas. Implementação da Política Nacional de Resíduos Sólidos. Revista de Administração Pública, Rio de Janeiro, n. 52, p. 51-52, jan./fev., 2018. Disponível em: http://www.scielo.br/pdf/rap/v52n1/19823134-rap-52-01-24.pdf Acesso em: 16 jan. 2019.

MANZANO, Jordi Jaria. El fundamento constitucional de los derechos de participación em materia de medio ambiente y su desarrollo em la ley 27/2006. In: SOLÉ, Antoni Pigrau (Org.). Acesso a la información, participación pública y acceso a la justicia em materia de medio ambiente: diez años del Convenio de Aahus. Barcelona: Ed. Atelier, 2008.

MELO, Milena Petters. Desenvolvimento sustentável: das Declarações internacionais à planificação estratégica e governance local. In: WOLKMER, Maria de Fátima S.; MELO, Milena Petters. Crise ambiental, direitos à agua e sustentabilidade: visões multidisciplinares. Caxias do Sul, RS: Educs, 2012. Disponível em: < https:// www.ucs.br/site/midia/arquivos/CRISE_AMBIENTAL_ EDUCS_E_BOOK.pdf>. Acesso em: 07 ago. 2018.

Desenvolvimento sustentável: das declarações internacionais à governance local. Revista Internacional de Direito Ambiental, ano v, n. 15, set./ dez. 2016. Caxias do Sul, RS: Plenum, 2016.

MINISTÉRIO DO MEIO AMBIENTE. Sinir. Levantamentos anteriores. 2018. Disponível em: http://sinir.gov.br/ levantamento-de-informacoes-das-unidades-da-federacao/ levantamentos-anteriores Acesso em: 16 dez. 2018.

MURO JR., Aldo. Aspectos legais da poluição do ar. Revista Internacional de Direito Ambiental, ano v, n. 15, set./dez. 2016. Caxias do Sul, RS: Plenum, 2016.

NUNES JÚNIOR, Amandino Teixeira. O Estado ambiental de Direito. Revista Jus Navigandi, Teresina, ano 10, n. 589, 17 fev. 2005. Disponível em: <https://jus. 
com.br/artigos/6340>. Acesso em: 9 ago. 2018.

O'DONNELL, Guillermo. Democracia, agência e estado: teoria com intenção comparativa. São Paulo: Paz e Terra, 2011.

PIOVESAN, Flávia; FACHIN, Melina Girardi. Direitos

humanos e meio ambiente. In: In: GALLI, Alessandra (Coord.). Direito socioambiental: homenagem a Vladimir Passos. Curitiba: Juruá, 2011.

PUREZA, José Manuel; FRADE, Catarina. Direito do ambiente. Coimbra: Faculdade de Economia da Universidade de Coimbra, 1998.

RODRIGUES, José Eduardo; FERNANDES, Valdir; PHILIPPI JR., Arlindo. Política e gestão ambiental no Brasil. In: GALLI, Alessandra (Coord.). Direito socioambiental: homenagem a Vladimir Passos. Curitiba: Juruá, 2011.

SACCOL, Ana Paula. A concepção de Estado no pensamento de Durkheim: Lições de sociologia. Revista Eletrônica dos Pós Graduandos em Sociologia Política da UFSC, v. 8, n. 1, jan./ jul., 2012. Disponível em: < https:// periodicos.ufsc.br/index.php/emtese/article/viewFile/18o65023.2012v9nipg6/23490>. Acesso em: 9 ago. 2018.

SARLET, Ingo. Teoria geral dos direitos fundamentais. In: SARLET, Ingo Wolfgang; MARINONI, Luiz Guilherme; MITIDIERO, Daniel. Curso de Direito Constitucional. 6. ed. São Paulo: Saraiva, 2017.

SARLET, Ingo, FENSTERSEIFER, Tiago. Estado socioambiental e mínimo existencial (ecológico?): algumas aproximações. In: SARLET, Ingo Wolfgang (Org.). Estado socioambiental e direitos fundamentais. Porto Alegre: Livraria do Advogado, 2010.

SCHIERA, Pierangelo. Estado Moderno. In: BOBBIO, Norberto; MATTEUCI, Nicola; PASQUINO, Gianfranco. Dicionário de política. v. 1. 11. ed. Brasília, DF: UnB, 1998.

SIRVINSKAS, Luís Paulo. Manual de direito ambiental. 4. ed. São Paulo: Saraiva, 2006.

SILVA, José Afonso da. Direito ambiental constitucional. 2. ed. São Paulo: Malheiros, 1998.

WEBER, Max. Economia e sociedade: fundamentos da sociologia compreensiva. v. 1. Brasília, DF: Editora Universidade de Brasília: São Paulo: Imprensa Oficial do Estado de São Paulo, 1999. 